\title{
Condições temporais e pessoais de Estudo em Universitários
}

\author{
Maria José Guimarães Carelli \\ Universidade São Francisco \\ Acácia Aparecida Angeli dos Santos ${ }^{1}$ \\ Universidade São Francisco
}

\begin{abstract}
Resumo
A etapa de formação universitária é de fundamental importância para a capacitação profissional e sua viabilidade depende de condições adequadas. Assim, o presente estudo teve como objetivo verificar as condições temporais e pessoais de estudo de universitários. Serviram como sujeitos 181 alunos concluintes dos cursos de Psicologia, Engenharia Civil e Farmácia, dos turnos diurno e noturno de uma universidade particular comunitária. Os dados foram coletados por meio de um questionário e foram encontradas diferenças significativas, tanto no que se refere às condições temporais como pessoais, entre alunos de diferentes cursos e turnos, identificando-se dificuldades que devem ser superadas pela utilização de estratégias de ensinoaprendizagem mais adequadas ao perfil e condições dos alunos, visando uma preparação para o enfrentamento das exigências profissionais do mundo atual.
\end{abstract}

Palavras chave: Universitário, Hábitos de Estudo, Ensino Superior, Condições de Estudo.

\section{Temporaly and personal conditions of study of university students}

\section{Summary}

The stage of university formation is very important for the professional training and its viability depends on appropriate conditions. Thus, the present study aimed to verify the temporary and personal conditions of study of university students. The subjects were 181 pre-graduates in their last year courses of PsychoIogy, Pharmacy, Civil Engineering, from Daytime and Evening periods of a private university. The data were collected via questionnaire, and significant differences were found, concerning the temporary and personal conditions between students of different courses and periods, identifying difficulties that should be overcome by the use ofteaching-leaming strategies more adapted to the profile and the students' conditions, seeking a preparation to coping the professional demands of the current world.

Key words: University, Study Habit, Higher Education, Study Conditions.

\section{Introdução}

A etapa de formação universitária exige uma série de atividades dos estudantes, para as quais devem ser garantidas condições mínimas necessárias para o equacionamento das dificuldades freqüentemente encontradas, de forma a viabilizar a formação humana e profissional aí pretendida.

É considerado de extrema importância conferir ao jovem universitário, nos dias de hoje, a idéia de que deva buscar sua participação na vida acadêmica dentro de uma realidade social, dinâmica e participativa, baseado num referencial teórico-metodológico e científico. Assim sendo, quando o jovem tem a possibilidade de estudar, esse processo representa sua oportunidade para

\footnotetext{
${ }^{1}$ Email: acacia@usf.com.br.
} 
transformação, passando a ver os estudos como requisito básico de ascensão pessoal e profissional (Souza, 1993; Serpa, 1998).

No entanto, cabem neste contexto questionamentos quanto à forma e condições de estudo a serem dadas aos alunos, que garantam sua busca de conhecimento. Segundo Mercuri (1992), a ausência dessas condições pode acarretar dificuldades para o aluno na viabilização de um estudo eficiente.

As Condições Temporais, consideradas como das mais relevantes, referem-se ao intervalo de tempo que o aluno tem para dedicar-se a trabalhos extra-classe, a fim de completar seus estudos e reforçar seu desempenho acadêmico.

De acordo com Morgan e Deese (1980), estudar de forma bem sucedida envolve um esforço integral na busca da aprendizagem. Assim, estudar e manter seus estudos em dia requer do aluno um planejamento de seu tempo, estabelecendo de antemão um plano de estudo para o dia, a semana e até mesmo para o ano letivo. Dessa forma, o aluno estará organizando-se acerca dos itens mais relevantes do programa educacional.

Planejar o tempo de forma adequada, segundo esses autores, não é exatamente a distribuição em "tantas horas" de estudo, e sim, buscar garantir um estudo eficiente por um período de tempo, porque muitas vezes, mesmo possuindo habilidade para os estudos, esta não será de grande utilidade se o aluno não dispuser adequadamente seu tempo ao empregá-la.

Muitas pesquisas já foram desenvolvidas com o objetivo de observar qual o intervalo de tempo de estudo é considerado como satisfatório ao aluno para garantir seu desempenho acadêmico. No entanto, alguns resultados contraditórios, referentes aos trabalhos já realizados, parecem dificultar uma conclusão a esse respeito, tal como se relata a seguir.

Embora tal observação possa ser confirmada por pesquisas que exploram a relação entre desempenho acadêmico e tempo de estudo, outros trabalhos, como o de Keith (1982), demonstram que os alunos, mesmo com poucas habilidades, mas que tiveram maiores oportunidades de tempo para a dedicação aos estudos, obtiveram melhor desempenho, o que se refletiu positivamente em suas notas escolares.

O mesmo não pode ser verificado nos estudos de D'Ydewalie, Swerts e Corte (1983), que observaram que a atenção maior não deve recair sobre o tempo total de número de horas de estudos e sim na forma como o aluno distribui seu tempo parcial nas diferentes atividades de estudos. Por outro lado, os autores verificaram que um tempo muito pequeno de estudo, como por exemplo, só para uma leitura, sem possibilidades de revisão, acarretaram resultados acadêmicos inferiores, quando comparados a um tempo que possibilitava aos alunos a organização da leitura e sua revisão.

Reforçando a idéia de que o tempo para o estudo extra-classe se faz necessário para garantir o desempenho acadêmico, embora com visão não conclusiva de quanto tempo é o "ideal" para os estudos extras, Souza (1993) conclui em sua pesquisa com alunos da Universidade Federal de Maringá que, em relação à dificuldade no desempenho acadêmico dos mesmos, dois são os fatores mais significativos: dificuldades pessoais e falta de tempo para os estudos, apontados por 33,89\% dos alunos pesquisados. Fica também continuado neste estudo que os alunos que trabalham, quando comparados aos que só estudam, têm menos tempo para se dedicarem aos estudos e com isso enfrentam maiores dificuldades para acompanhar o curso, decorrendo conseqüentemente, um menor rendimento acadêmico. 
Outro aspecto que contribui para o esclarecimento da importância do tempo como condição favorável para o estudo, foi verificado por Sonneville (1992), em sua pesquisa realizada com alunos da Faculdade de Educação do Estado da Bahia (FAEEBA). Este autor conclui que uma grande parte dos alunos reconhece a importância do tempo de estudo extra-classe e percebe a necessidade de melhorar essa situação. Consideram, entretanto, que esta deficiência está relacionada à falta de tempo por causa do trabalho. Por outro lado, conclui ainda o autor que a análise quantitativa dos dados referentes à pesquisa realizada mostrou que não existe relação entre trabalho e tempo de estudo extraclasse, não lhe sendo possível apontar as principais causas da falta desse tipo de estudo entre os alunos da FAEEBA.

Paul e Ribeiro (1991), interessados em caracterizar a clientela dos diferentes cursos da cidade de Fortaleza, detectaram que os alunos que trabalham dedicam menos tempo aos estudos extraclasse, tendo sido preservado, no entanto, o mesmo tempo de lazer. Verificaram algumas diferenças associadas, possivelmente, à hierarquia dos cursos, sendo que os de maior prestígio social (que correspondiam às melhores carreiras no mercado de trabalho) necessitavam de um tempo médio maior de estudo em relação aos cursos de menor prestígio ( ligados a carreiras menos valorizadas).

Por Condições Pessoais consideram-se os aspectos ligados ao repertório comportamental, assim como às condições físicas do aluno associadas ao seu desempenho. As habilidades de estudos, que são estratégias de aprendizagem independentes, segundo Mercuri (1992), em muito demonstram como as deficiências pessoais ficam evidenciadas no desempenho acadêmico.

A autora, por outro lado, aponta que na literatura muitas são as formas de definição para habilidades de estudos. Assim sendo, alguns autores definem como "habilidades de que o aluno precisa para estudar", ou como "processos de aprendizagem", enquanto outros a definem como "competência associada a uma série de fatores desenvolvidos pela escola".

Marshak e Burkle (1981) consideram que habilidades de estudo são procedimentos para aprender e resolver problemas e que as mesmas podem ser ensinadas, para que os alunos adquiram conhecimentos, competência com maior responsabilidade sobre sua própria aprendizagem.

Parece que qualquer que seja a definição dada para habilidades de estudo, é inegável sua importância, em termos de condições pessoais satisfatórias, para assegurar uma real aprendizagem. Garantir ao aluno estratégias adequadas de estudo, favorecendo suas condições pessoais, a fim de garantir suas habilidades de estudo, tem sido objeto de preocupação de muitos estudiosos que trabalham com universitários.

Entre tantos fatores influenciadores do rendimento acadêmico, sabe-se que uma das características que determina a evolução e realização acadêmica é a ampliação do universo cultural do estudante. No entanto, tal fato não está só relacionado às atividades sistemáticas em sala de aula, como também ao envolvimento em tarefas extra-classe: leitura de textos, resoluções de problemas, envolvimento com pesquisa, entre outras atividades complementares, que favorecem o desempenho acadêmico.

Nesse sentido, pesquisadores preocupados com questões educacionais destacam a importância e a necessidade dos alunos dedicarem-se a períodos de estudos extra-classe, para garantirem um reforço na aprendizagem, culminando conseqüentemente, numa formação acadêmica mais satisfatória. Dentre as atividades extra-aula, a que tem sido mais ressaltada é a leitura e os processos nela envolvidos, especialmente, a compreensão de textos. Em função dessa preocupação, vários autores têm se dedicado à pesquisa sobre o tema, ressaltando sua importância para uma boa 
formação acadêmica, visto que a capacidade de ler e entender textos, propiciaria uma aprendizagem eficaz durante e após a realização do curso, na medida em que favoreceria a autonomia para aprender (Santos, 1 990a; Oliveira, 1993).

Mercuri (1992) também ressalta que uma das principais condições pessoais para que o aluno possa garantir favoravelmente sua habilidade de estudo e de domínio de conteúdos, é a leitura. A partir de sua pesquisa sobre condições de estudos de alunos de graduação da Unicamp, a autora considera que o sucesso do aluno depende do saber ler, interpretar, criticar e também usar sua criatividade na busca do conhecimento.

O que se verifica a respeito do assunto é que muitas são as pesquisas desenvolvidas, procurando relacionar a importância do hábito de leitura como parte do repertório básico dos estudantes e avaliar o quanto um melhor nível de compreensão favorece a relação ensinoaprendizagem.

Santos (1990b) destaca que conhecer e analisar as características do aluno-leitor é de extrema importância para o processo ensino-aprendizagem, principalmente no que se refere ao universitário, que se encontra na última etapa de educação formal, o que estará se refletindo diretamente na qualidade de sua formação e em seu desempenho profissional.

Tais dificuldades são ainda mais evidentes em alunos do curso superior noturno, visto que para eles a questão da condição de estudo parece conter uma resolução mais difícil, tal como se refere Andrade e Sposito (1986).

Os autores tecem considerações quanto ao fato de que, na condição de trabalhador e aluno, poucas são as oportunidades para crescer intelectualmente, ficando sua formação profissional a desejar. O estudo que realizaram permitiu-lhes observar que esses alunos enfrentaram problemas em sua trajetória acadêmica e em seu universo existencial, com reflexos em seu desempenho acadêmico e evidências no nível de dificuldades orais e escritas, que os alunos demonstraram. Além disso, ficou bem caracterizado: a) aversão aos textos de conteúdo mais complexo; b) ausência de um pensamento mais crítico; c) dificuldade de generalização de aprendizagem, acarretando, conseqüentemente, um baixo rendimento escolar.

Muito apropriadamente, os autores insistem em que o aluno que trabalha deveria ter oportunidade de obter um rendimento escolar satisfatório, a fim de poder enfrentar um mercado de trabalho competitivo. Assim, deve ele ter o direito de obter um ensino de boa qualidade, com metodologia e didática, que sejam adequadas à sua condição de aluno-trabalhador, conseguindo aprender a estudar em própria universidade.

Contribuindo para o esclarecimento da importância sobre a condição pessoal de estudo, Dominguez e Morelli (1984) fizeram um levantamento das dificuldades de estudo em universitários, que revelou que a maioria deles não está devidamente orientada para conseguir um desempenho ideal. Tal situação parece estar relacionada ao fato de não possuírem as habilidades adequadas para desenvolverem seus trabalhos acadêmicos, o que, na maior parte das vezes, é reflexo da falta de preparação no $1^{\circ}$ grau. Além da dificuldade relatada, os autores citam a questão da interação professor-aluno que, se for inadequada, causa efeitos negativos no processo ensinoaprendizagem.

Balzan (1988), em um questionamento com alunos de vários cursos, em fase de conclusão, detectou que a baixa qualidade do ensino superior recai sobre alguns fatores, como: a) falta de didática do professor, apontada por todos os alunos que foram questionados; b) desintegração entre 
teoria e prática; c) ausência de projetos que tornassem o processo ensino-aprendizagem dinâmico e motivador.

Outros pontos levantados, por meio desta pesquisa, apontam para demais fatores que também contribuem para a baixa qualidade de ensino, tais como: a falta de infra-estrutura, tanto da instituição como um todo, como das unidades de ensino específicas; o problema de transporte, bibliotecas, condições dos equipamentos e dos laboratórios, além da questão salarial, envolvendo professores e funcionários.

Em um estudo a respeito do ensino superior privado no Brasil, Fernandez (1993) colheu dados com universitários pertencentes a três instituições particulares, para a construção do diagnóstico .das mesmas e pôde concluir que falta qualidade de ensino nessas instituições analisadas, no que diz respeito a: a) procedimentos pedagógicos e metodologias pouco satisfatórias dos docentes; b) infra-estrutura mínima necessária para o funcionamento da instituição, abrangendo baixa qualidade ou inexistência de material pedagógico, bibliotecas e laboratórios; c) sistema de avaliação comprometido, ocasionando a inadequação de todo o processo pedagógico; d) má qualidade na formação profissional, refletida no currículo escolar inadequado. Tais constatações denunciaram a incompatibilidade existente na relação ensino-aprendizagem e evidenciaram o déficit de alguns cursos.

Dado o exposto ao longo deste estudo, parece ser inegável que os autores citados apresentaram uma ótica conclusiva convergente, considerando insatisfatória a questão da qualidade do ensino superior no Brasil, refletindo, portanto, as condições de estudo inadequadas proporcionadas ao aluno, o que influencia negativamente seu desempenho acadêmico e, posteriormente, seu desempenho profissional. Todos os autores ressaltam a real importância e a urgência de se rever, no contexto educacional, a questão das condições de estudo, em suas diversas dimensões.

Assim, acredita-se que a identificação das condições de estudo de alunos da USF permitirá a busca de alternativas facilitadoras que lhes darão melhores possibilidades de aproveitamento escolar, a partir das quais poderá se viabilizar uma formação profissional mais adequada e favorecer uma atuação crítica e criativa indispensável ao perfil do ser humano do nosso tempo.

Tendo em vista os aspectos considerados, este trabalho foi proposto com o seguinte objetivo de identificar e comparar as condições temporais e pessoais de estudo de alunos do último ano de graduação, dos turnos diurno e noturno.

\section{Método}

Sujeitos

Serviram como sujeitos para a presente pesquisa 181 alunos concluintes de cursos de Psicologia, Engenharia Civil e Farmácia de uma universidade particular comunitária, que foram selecionados por serem, em cada uma das áreas (biológicas, exatas e humanas), os Únicos que se repetem, nos turnos diurno e noturno, o que possibilitaria uma comparação dos dados obtidos, em função desta variável. O percentual de respondentes correspondeu, respectivamente, a 72\%,82\% e 75\% do total de alunos dos referidos cursos.

\section{Material}

Foi utilizado um questionário, adaptado dos utilizados por Castanho (1989) e Mercuri (1992), composto de 77 questões. A partir dele obteve-se informações quanto: a) identificação do sujeito; b) 
ocupação; c) motivo pelo qual trabalha; d) local de residência; e) tempo de deslocamento para chegar à universidade; f)escolaridade dos genitores e cônjuge; g) caracterização das escolas freqüentadas anteriormente; h) turno e número de reprovações nos ensinos fundamental e médio. Para a obtenção destes - dados foi utilizado um total de 37 perguntas.

As 40 perguntas restantes serviram para caracterizar o tempo utilizado para estudar (9 questões); as condições pessoais (24 questões). As outras 7 questões, que investigaram as condições de espaço físico e condições materiais, não foram abordadas no presente trabalho.

\section{Procedimento}

Para a coleta dos dados, os alunos foram previamente orientados através de instruções escritas no início do questionário, no qual também havia uma carta de apresentação das pesquisadoras, justificando os motivos de sua aplicação. Os professores de cada sala, no dia previamente estipulado, conduziram a aplicação do questionário, entregando-o aos alunos presentes naquela data.

\section{Resultados e Discussão}

A análise dos dados aqui realizada inclui apenas os aspectos concernentes às condições temporais e pessoais de estudo dos sujeitos, cujos resultados são apresentados descritivamente através de freqüências e porcentagens e também por meio do cálculo do qui-quadrado, com a finalidade de observar a significância probabilística das diferenças referentes às amostras estudadas, entre os diferentes cursos e turnos. Foi considerado $\mathrm{p} \sim 0,05$ como nível significativo.

O tratamento estatístico foi elaborado considerando-se a individualidade dos cursos de Psicologia, Farmácia e Engenharia Civil, tendo em vista não serem grupos homogêneos, o que não permitiu estatisticamente conclusões com somatórias de períodos (3 cursos Noturno X 3 cursos Diurno). Sendo assim, toda a referência de resposta de um período foi resultado da média de resposta de cada curso.

Os resultados relativos às condições de estudo serão apresentados na seguinte ordem:

1. condições temporais e

2. condições pessoais.

Vale ressaltar que em todas as questões analisadas houve uma variação no número de respostas, que nem sempre correspondeu ao número total de informantes em função de: a) existência de respostas anuladas por terem sido assinaladas mais de uma alternativa; b) ausência de respostas por parte do informante; c) dependência da resposta à questão anterior.

\section{Condições temporais}

Em relação ao tempo extra despendido para o estudo, tal como foi considerado como condição temporal, a análise dos dados mostrou que os alunos do diurno comportaram-se de forma mais semelhante entre si no que se refere a estudar só nos finais de semanas $(58,56 \%)$ e estudar alguns dias e todos os dias da semana $(41,44 \%)$, do que os alunos do noturno que declararam estudar mais só nos finais de semana (72,80\%).

Observou-se uma diferença significativa para o curso de Psicologia noturno em relação ao diurno ( $\mathrm{p}=0,0114$ ), quanto ao estudar no final de semana. Assim, percebeu-se que os alunos de Psicologia noturno estudam mais nos finais de semana (76,67\%), em comparação aos de Psicologia 
diurno (25\%). Outra diferença significativa $(\mathrm{p}=0,0132)$ foi detectada no curso de Farmácia noturno, cujos alunos estudam mais em alguns/todos os dias (45,24\%), quando comparados aos de Farmácia diurno (16\%).

Quanto ao tempo médio de estudo extraclasse que os alunos empregavam para estudar, registrou-se que os alunos do curso de Psicologia diurno são os que têm um tempo médio maior de estudo (11,5 h/sem.), quando comparados aos alunos dos outros dois cursos diurnos (Farmácia= 6,5 $\mathrm{h} / \mathrm{sem}$; Eng ${ }^{\mathrm{a}}$ Civil= 6,0h/sem). Por outro lado, observou-se que foram os alunos de Psicologia noturno os que têm um tempo médio de estudo menor (5,5 h/sem), quando comparados aos alunos dos dois outros cursos noturnos (Farmácia= 8,5h/sem; Eng ${ }^{\text {a }}$ Civil= 6h/sem). Quanto aos alunos do curso de Engenharia Civil diurno e noturno evidenciou-se um equilíbrio para o tempo médio de estudo (6h/sem). Frente a tais dados, pode-se observar que os alunos têm pouco tempo de estudo extraclasse. Considerando que a maioria declarou estudar mais nos fins de semana, é possível inferir que os alunos estudam menos que uma hora por dia, em média, tempo este muito reduzido para garantir um complemento adequado e necessário à formação profissional que se deseja.

Tal fato fica ainda mais relevante em relação ao alunos do curso de Farmácia diurno, que apesar de serem os que menos trabalham, são também os que têm menos horas semanais de estudo, quando comparados aos alunos do noturno que em sua grande maioria, alegam não ter tempo de estudar, devido à carga horária dedicada ao trabalho. Resultados semelhantes em relação ao pouco tempo médio semanal de estudo extra-classe podem ser verificados nos estudos realizados por Paul \& Ribeiro, 1991, Sonneville, 1992 e Sousa, 1993.

Julgou-se interessante saber como os alunos percebiam o tempo que tinham para o estudo extra, qualificando-o como suficiente ou não. Assim, foi possível verificar que os alunos dos três cursos envolvidos no presente estudo indicaram ser o tempo que têm, insuficiente para os seus estudos (diurno= 56,43\% e noturno= 83,05\%). Quanto a essa insuficiência do tempo para estudo, houve diferença estatisticamente significativa entre os alunos dos cursos de Farmácia e Engenharia noturnos, em relação ao diurno (Farmácia $\mathrm{p}=0,0391$ e Engenharia $\mathrm{p}=0,0131$ ), visto que os do noturno consideram seu tempo para estudo insuficiente, diferentemente dos do diurno.

A principal razão apresentada para a insuficiência de tempo para os estudos, principalmente entre os alunos do noturno, foi a necessidade de dedicar muito tempo ao trabalho. Confirmando o prejuízo de tempo, os alunos do noturno, mais que os alunos do diurno, apontaram ter só os finais de semana para estudar.

Verificou-se, inclusive, diferença estatisticamente significante entre os alunos do curso de Psicologia noturno, em relação aos alunos do curso de Psicologia diurno, o que parece justificar o fato de serem os alunos de Psicologia noturno os que apontaram ter menor tempo médio de estudo semanal. A mesma situação ocorre de maneira menos acentuada com os estudantes de Engenharia noturno, tendo-se como exceção os de Farmácia noturno, que declararam dedicar um tempo extra-classe maior que os alunos de Farmácia do diurno.

Os motivos alegados para a insuficiência de tempo para estudos extra-classe aparecem na Tabela 1: 
Tabela 1. Motivos da insuficiência de tempo para os estudos

\begin{tabular}{|c|c|c|c|c|c|c|c|c|c|c|c|c|c|c|c|c|}
\hline & \multicolumn{9}{|c|}{ DIURNO } & \multicolumn{7}{c|}{ NOTURNO } \\
\hline & Psicologia & \multicolumn{2}{|c|}{ Engenharia } & \multicolumn{2}{|c|}{ Farmácia } & \multicolumn{2}{|c|}{ Total } & \multicolumn{2}{|c|}{ Psicologia } & \multicolumn{2}{|c|}{ Engenharia } & \multicolumn{2}{|c|}{ Farmácia } & \multicolumn{2}{c|}{ Total } \\
\hline & $\mathrm{F}$ & $\%$ & $\mathrm{f}$ & & $\mathrm{F}$ & $\%$ & $\mathrm{f}$ & $\%$ & $\mathrm{f}$ & $\%$ & $\mathrm{~F}$ & $\%$ & $\mathrm{~F}$ & $\%$ & $\mathrm{f}$ & $\%$ \\
\hline 1 & 3 & 50,00 & 10 & 71.43 & $\mathrm{O}$ & $\mathrm{O}$ & 13 & 40,48 & 24 & 85.71 & 23 & 79,31 & 20 & 62,50 & 67 & 75,84 \\
\hline 2 & 2 & 33,33 & 0 & 0 & 5 & 41,67 & 7 & 25,00 & 0 & 0 & 0 & 0 & 6 & 18.75 & 6 & 6,25 \\
\hline 3 & 1 & 16,67 & 4 & 28,57 & 7 & 58,33 & 12 & 34,52 & 4 & 14,29 & 6 & 20,69 & 6 & 18.75 & 16 & 17,91 \\
\hline Total & 6 & 100 & 14 & 100 & 12 & 100 & 32 & 100 & 28 & 100 & 29 & 100 & 32 & 100 & 89 & 100 \\
\hline
\end{tabular}

1- Tempo dedicado ao trabalho fora da universidade; 2- Excesso de carga horária na universidade; 3-Compromissos domésticos / sociais.

Dos alunos que consideraram o tempo como sendo insuficiente para os seus estudos, observou-se que houve um predomínio nos três cursos noturnos dos que apontaram como sendo o "principal motivo da insuficiência para os estudos" o fato de gastarem um tempo maior dedicandose ao trabalho fora da universidade (75,84\%), enquanto que para os alunos dos três cursos do diurno, o motivo da insuficiência se distribuiu de forma mais eqüitativa entre o tempo gasto no trabalho fora da universidade (40,48\%) e compromissos domésticos e/ou sociais (34,52\%).

Uma grande parcela de alunos do diurno e noturno afirmou que o "período reduzido para os estudos" influencia negativamente seus estudos (diurno $=43,19 \%$ e noturno $=50,96 \%$ ), o que foi condizente com os resultados obtidos por Mercuri (1992), cujos sujeitos apontaram a condição temporal com sendo a mais influente para seus estudos, reconhecendo o seu potencial prejudicial no desempenho, quando inadequada.

Considerando os dados aqui analisados e discutidos, pode-se observar que a condição temporal é um fator importante e mal administrado pelos universitários, quer pelo fato de serem alunos-trabalhadores, quer pelo fato de terem muitos compromissos sociais e/ou familiares. É possível que em função dessa razão, principalmente, os alunos do noturno tenham afirmado ter prejuízos em relação ao seu desempenho acadêmico, pelo pouco tempo disponível para estudar, só podendo fazê-la nos finais de semana.

Esses dados refletem a necessidade de aprendizagem do aluno quanto a métodos de estudos mais adequados. Neste sentido, a universidade deveria atuar mais diretamente, oferecendo ao aluno orientação quanto a melhor utilização de seu tempo e incentivar o uso dos espaços disponíveis existentes no campus de cada faculdade. Para tanto, parece ser indispensável a implantação de serviços psicopedagógicos para universitários, similares aos já existentes em algumas universidades brasileiras (Hoirisch; Barros \& Souza, 1993; Serpa, 1998).

Um estudo anterior, realizado na Universidade São Francisco por Santos (1997), demonstrou a eficácia de um programa psicopedagógico para alunos iniciantes de Psicologia e Análise de Sistemas, que não só melhoraram seu nível de compreensão em leitura, como também desenvolveram habilidades de estudo mais adequadas às exigências do ensino superior.

De modo geral, observou-se que os dados aqui obtidos são semelhantes a outros relativos à condição temporal de estudo, tais como os encontrados nos estudos de D'Ydewalle e cal., 1987; Paul e Ribeiro, 1991; Sonneville, 1992; Mercuri, 1992 e Souza, 1993. 


\section{Condições pessoais}

Foram considerados como condições pessoais as condições físicas associadas ao desempenho acadêmico, bem como os aspectos ligados ao repertório comportamental dos alunos.

Investigando-se a disposição física para os estudos, tendo em vista que alegações de sono e cansaço são freqüentes entre os alunos, como explicação para o não cumprimento de algumas atividades acadêmicas, verificou-se que a frequiência média obtida para o "deixar de realizar as atividades devido ao sono e cansaço" entre o total de alunos foi de $78 \%$, sendo que entre os alunos do diurno foi observada uma diferença menor entre deixar $(45,11 \%)$ e não deixar $(54,89 \%)$ as atividades de estudar devido ao sono e cansaço.

Com relação a esta variável, houve uma diferença significativa para as turmas de Engenharia noturno e diurno $(\mathrm{p}=0,0119)$ e Psicologia noturno e diurno $(\mathrm{p}=0,0001)$, parecendo que para os alunos do turno noturno destes cursos, o sono e o cansaço constituem um empecilho maior para as atividades de estudos.

Considerou-se relevante compreender os motivos para esses dois fatores, tendo-se em vista o prejuízo de suas atividades de estudo. As respostas obtidas estão apresentadas na Tabela 2.

No que se refere aos "motivos do sono e cansaço" que têm prejudicado as atividades de estudo dos alunos foi possível detectar-se que os alunos do diurno atribuíram o fator sono a: compromissos com o trabalho extra-universidade (38,89\%); grande número de horas-aula na universidade (26,59\%), excesso de prática esportiva e programas sociais noturnos (23,81\%). Dentre os alunos de Farmácia diurno observou-se como principais motivos: excesso de aulas na universidade (71,43 \%) e excesso de programação noturna (21.43\%). Em relação aos alunos do noturno, o sono e cansaço foram atribuídos, principalmente, ao fato de terem muitos compromissos com o trabalho extra-universidade (65,46\%), sendo os alunos de Psicologia noturno aqueles que apontaram um índice maior para compromissos com o trabalho (76,67\%), como a principal razão para que sono e cansaço levassem a um prejuízo nas suas atividades de estudo.

Foi possível observar que os alunos de Farmácia noturno comportaram-se de forma diferenciada em relação aos alunos de Farmácia diurno, visto que os primeiros apontaram o fato de trabalhar em excesso como principal causa (48,28\%), enquanto que entre os alunos do diurno esse mesmo fator não foi apontado por ninguém ( $0 \%)$.

Tabela 2. Motivos do sono e cansaço entre os alunos

\begin{tabular}{|c|c|c|c|c|c|c|c|c|c|c|c|c|c|c|c|c|}
\hline & \multicolumn{8}{|c|}{ DIURNO } & \multicolumn{8}{|c|}{ NOTURNO } \\
\hline & \multicolumn{2}{|c|}{ PsicoloQia } & \multicolumn{2}{|c|}{ Ennenharia } & \multicolumn{2}{|c|}{ Farmácia } & \multicolumn{2}{|c|}{ Total } & \multicolumn{2}{|c|}{ Psicolonia } & \multicolumn{2}{|c|}{ Ennenharia } & \multicolumn{2}{|c|}{ Farmácia } & \multicolumn{2}{|c|}{ Total } \\
\hline & $\mathrm{F}$ & $\%$ & $\mathrm{~F}$ & $\%$ & $\mathrm{~F}$ & $\%$ & $\mathrm{~F}$ & !! & $\mathrm{F}$ & $\%$ & $\mathrm{~F}$ & $\%$ & $\mathrm{~F}$ & $\%$ & $\mathrm{~F}$ & $\%$ \\
\hline 1 & 2 & 66.67 & 6 & 50 & $\mathrm{O}$ & $\mathrm{O}$ & 8 & 38.89 & 23 & 76,67 & 20 & 71,43 & 14 & 48.28 & 57 & 65.46 \\
\hline 2 & $\mathrm{O}$ & $\mathrm{O}$ & 1 & 8.33 & 10 & 71,43 & 11 & 26.59 & $\mathrm{O}$ & $\mathrm{O}$ & 1 & 3,57 & 5 & 17,24 & 6 & 6.94 \\
\hline 3 & $\mathrm{O}$ & $\mathrm{O}$ & 3 & 25 & 1 & 7.14 & 4 & 10.71 & 2 & 6.67 & 3 & 1071 & 5 & 1724 & 10 & 11.54 \\
\hline $4 *$ & 1 & 33,33 & 2 & 16,67 & 3 & 21,43 & 6 & 23.81 & 5 & 16.66 & 4 & 14.29 & 5 & 17,24 & 14 & 16.06 \\
\hline Total & 3 & 100 & 12 & 100 & 14 & 100 & 29 & 100 & 30 & 100 & 28 & 100 & 29 & 100 & 87 & 100 \\
\hline
\end{tabular}

1- Compromissos com o trabalho extra-universidade; 2-Excesso carga horária na universidade; 3- Compromissos domésticos/ familiares

4- Outros*

* Por outros motivos pelos quais o sono e cansaço prejudicam as atividades de estudo foram consideradas as respostas dadas pelos sujeitos 
em: excesso de prática esportiva e/ou programas sociais noturnos; motivos variados

O reconhecimento de que o sono e cansaço acarretam prejuízo para o estudo está provavelmente relacionado à situação, detectada por ocasião da investigação das condições temporais, na qual se verificou que os alunos têm hábito de dormir tarde por estarem comprometidos com o trabalho ou envolvidos com atividades sociais ou familiares, bem como pelo tempo que gastam para voltarem às suas residências.

Quanto ao reconhecimento de que as "condições físicas" podem influenciar negativamente o rendimento acadêmico, observou-se que os alunos dos três cursos diurnos indicaram que às vezes isso acontece (51,05\%). Por outro lado, os alunos dos três cursos noturnos responderam na mesma proporção (43,16\%), tanto para a alternativa todas/muitas vezes, como para a alternativa às vezes.

No que se refere a condições pessoais relacionadas aos aspectos do repertório comportamental do aluno, julgou-se importante identificar as principais fontes nas quais os alunos obtêm informações. Assim, pode-se observar que os alunos dos três cursos noturnos disseram "obter suas informações", principalmente, a partir de leitura de jornais (38,93\%), enquanto que os alunos dos três cursos diurnos declararam obtê-las a partir de noticiário de TV (43,34\%). Entretanto, os alunos do curso de Farmácia diurno foram os que apresentaram um índice maior de obtenção de informações a partir de noticiário de TV (66,67\%); todavia, os alunos de Psicologia noturno foram os que indicaram, em maior freqüência, obter informações através de leitura de jornais (43,34\%). Resultados semelhantes foram alcançados por Santos (1990a); Paul \& Ribeiro (1991) e Pellegrini (1996), com base na realização de seus estudos sobre hábitos de leitura e formas de atualização em universitários.

Partindo-se do pressuposto que a forma de estudar é uma importante condição pessoal relacionada ao desempenho acadêmico foi perguntado aos alunos sobre como eles estudavam. Verificou-se que os alunos dos três cursos e turnos declararam estudar sozinhos (diurno $=88,46 \% \mathrm{e}$ noturno $=83,33 \%$ ). Tal fato ficou mais evidente no curso de Psicologia noturno, no qual 94,12\% dos alunos afirmaram preferir estudar sozinhos, quando comparados aos que afirmaram estudar em grupo (5,88\%). Porém, observou-se que no curso de Engenharia Civil diurno houve pouca diferença entre estudar sozinho $(57,14 \%)$ e estudarem grupo (42,86\%). Assim, pôde-se observar que os alunos do noturno comportaram-se de forma semelhante com relação a esta variável, quando comparados aos alunos do diurno, o que parece explicar o fato de não ter sido observada diferença significativa entre eles.

A maior freqüência de respostas de estudar sozinho pode ter ocorrido não pela simples preferência dos alunos, mas muito mais pelo fato de que eles têm poucas alternativas em fazê-Io em grupo, devido a fatores como pouco tempo disponível durante a semana, distância de moradia entre os colegas, horários de trabalho incompatíveis e falta de espaços adequados para reuniões coletivas. Entretanto, o reconhecimento da importância do aprender a trabalhar em equipe, como forma de desenvolver habilidades de cooperação e de preparar o futuro profissional para integrarem equipes interdisciplinares, cada vez mais comuns nos vários campos profissionais, exige da universidade que haja espaços adequados para tanto e dos professores, criatividade suficiente para a implementação de práticas educativas que viabilizem uma forma efetiva de trabalhos em grupo.

Outro aspecto investigado foi a forma pela qual os alunos estudam textos escritos, visto ser esta uma das tarefas mais freqüentemente solicitadas a eles. Verificou-se que os alunos dos três cursos e turnos "estudam os textos escritos", principalmente lendo, sublinhando e anotando (diurno 
$=71,59 \%$ e noturno $=63,74 \%$ ). Os alunos de Psicologia noturno foram os que apresentaram a freqüência mais alta de respostas nesta categoria (93,94\%).

Com relação a esta variável, a análise estatística dos dados apontou para a existência de diferença significativa $(\mathrm{p}=0,0179)$ entre os alunos do curso de Engenharia noturno em relação ao diurno, os quais declararam estudar textos escritos apenas lendo e anotando (61,54\%), enquanto os alunos de Engenharia diurno o fazem lendo, sublinhando e anotando (72,73\%).

Sendo a leitura uma outra atividade bastante requisitada aos alunos, foi-lhes perguntado sobre suas "dificuldades em relação a compreender os textos indicados pelos professores". A Tabela 3 traz a distribuição das freqüências das respostas obtidas.

Quando analisados os dados dos três cursos do diurno e do noturno, observou-se que a maioria dos alunos afirmou não ter dificuldades na compreensão de textos (diurno $=74,62 \%$ e noturno $=52,13 \%$ ). Porém, verificou-se que os alunos de Psicologia diurno e noturno foram os que mais apontaram dificuldades de compreensão de textos. Os alunos de Psicologia diurno que admitiram ter dificuldades, atribuíram-na a problemas pessoais, como por exemplo, falta de conhecimentos básicos na área do conteúdo (33,33\%). Já os alunos do curso de Psicologia noturno associaram suas dificuldades a aspectos inerentes ao próprio texto, como por exemplo: excesso de termos técnicos, má qualidade da tradução (35,29\%).

A freqüente alegação de "dificuldades para redigir" foi investigada junto aos alunos e suas respostas acham-se representadas na Tabela 4.

A média de alunos do diurno que declarou não ter dificuldades na redação dos trabalhos solicitados (72,63\%) foi maior do que do noturno (56,36\%). Os alunos do curso de Engenharia diurno foram os que com maior freqüência declararam não ter dificuldades na redação dos trabalhos (78,57\%), enquanto que os alunos de Psicologia noturno foram os que aparentaram a menor freqüência em relação a esse aspecto (26,47\%). As principais razões apontadas para essa situação foram decorrentes das dificuldades inerentes ao próprio trabalho, como: complexidade do tema e quantidade e qualidade de material bibliográfico (41,18\%). Foram detectadas ainda dificuldades ligadas a aspectos pessoais, tais como: dificuldades em expressar idéias e organização da estrutura do trabalho $(26,47 \%)$.

A partir das análises dos resultados referentes às condições pessoais de estudos, observou-se que a maioria dos alunos do noturno reuniu algumas características a serem consideradas. Assim, em relação à dificuldade de compreensão de textos e/ou redação, foram os alunos de Psicologia noturno que apontaram possuir maiores dificuldades em compreender e redigir um texto, apresentando como motivos principais, dificuldades de ordem pessoal e aspectos inerentes ao texto. Este dado provavelmente está relacionado ao fato de que foram estes alunos os que reuniram um maior número de características desfavoráveis ao desempenho acadêmico, tais como: menor tempo médio semanal disponível para estudo; estudos extraclasse só nos finais de semana; maior número de horas semanais de trabalho. 
Tabela 3. Dificuldades na compreensão dos textos

\begin{tabular}{|c|c|c|c|c|c|c|c|c|c|c|c|c|c|c|c|c|}
\hline & \multicolumn{8}{|c|}{ DIURNO } & \multicolumn{8}{|c|}{ NOTURNO } \\
\hline & \multicolumn{2}{|c|}{ Psicologia } & \multicolumn{2}{|c|}{ Engenharia } & \multicolumn{2}{|c|}{ Farmácia } & \multicolumn{2}{|c|}{ Total } & \multicolumn{2}{|c|}{ Psicologia } & \multicolumn{2}{|c|}{ Engenharia } & \multicolumn{2}{|c|}{ Farmácia } & \multicolumn{2}{|c|}{ Total } \\
\hline & $\mathrm{F}$ & $\%$ & $\mathrm{~F}$ & $\%$ & $\mathrm{~F}$ & $\%$ & $\mathrm{~F}$ & $\%$ & $\mathrm{~F}$ & $\%$ & $\mathrm{~F}$ & $\%$ & $\mathrm{~F}$ & $\%$ & $\mathrm{~F}$ & $\%$ \\
\hline 1 & 6 & 66,67 & 23 & 85,19 & 18 & 72 & 47 & 74,62 & 10 & 29,41 & 26 & 72.23 & 23 & 54.76 & 59 & 52,13 \\
\hline 2 & 3 & 33,33 & 3 & 11.11 & 2 & 8 & 8 & 17.48 & 6 & 17,65 & 6 & 16,66 & 10 & 23,81 & 22 & 19,37 \\
\hline 3 & $\mathrm{O}$ & $\mathrm{O}$ & $\mathrm{O}$ & $\mathrm{O}$ & 4 & 16 & 4 & 5,33 & 12 & 35,29 & $\mathrm{O}$ & $\mathrm{O}$ & 6 & 14,29 & 18 & 16,53 \\
\hline 4 & $\mathrm{O}$ & $\mathrm{O}$ & 1 & 3.70 & 1 & 4 & 2 & 2,57 & 6 & 17,65 & 4 & 11,11 & 3 & 7,14 & 13 & 11.97 \\
\hline Total & 9 & 100 & 28 & 100 & 25 & 100 & 62 & 100 & 34 & 100 & 36 & 100 & 42 & 100 & 112 & 100 \\
\hline
\end{tabular}

l-Não tem dificu1dade na compreensão dos textos; 2- Sim. e decorrem principalmente de problemas pessoais; 3- Sim. e decorrem principalmente de aspectos inerentes ao texto; 4- Sim. e decorrem principalmente da falta de trabalhos. debates e orientação sobre o texto.

Os alunos foram inquiridos sobre como "resolvem as dúvidas" que apresentam sobre os assuntos estudados. Observou-se, a partir dos dados analisados, que os alunos dos três cursos e turnos apontaram como alternativa para a resolução de dúvidas a procura aos colegas (noturno = $63,55 \%$ e diurno $=62 \%$ ). A maior concentração de frequiência nesta categoria deu-se entre os alunos do curso de Farmácia noturno (76,93\%), ao mesmo tempo que foram eles os que indicaram a menor freqüência para a categoria de procurar o professor para resolverem suas dúvidas (7,69\%).

A "realização de atividades de estudar" também foi investigada junto aos alunos, sendo que a maior freqüência de respostas dos alunos dos três cursos e turnos concentrou-se na alternativa na qual declaravam que já sabiam estudar antes de entrar na universidade (diurno $=50,79 \%$ e noturno $=44,84 \%$ ). Quando foram analisadas as respostas dos alunos dos três cursos noturnos observou-se uma diferença mínima entre os que afirmaram saber estudar antes de entrar na universidade $(44,84 \%)$ e ter aprendido a estudar na universidade (42,42\%). No entanto, a maioria dos alunos do curso de Farmácia noturno declarou ter aprendido a estudar na universidade (53,66\%).

A maioria dos alunos dos três cursos e turnos que indicou ter aprendido a estudar na universidade afirmou tê-lo feito a partir de seu desempenho pessoal (diurno $=80,56 \%$ e noturno $=72,42 \%$ ). Não foram detectadas diferenças estatisticamente significativas entre os diversos cursos e turnos.

Este fato talvez, seja explicativo para a dificuldade de compreensão e redação de texto, parecendo existirem causas anteriores à universidade, uma vez que quase metade dos alunos envolvidos na presente pesquisa afirmou não saber estudar e/ou aprendeu a fazê-lo depois da entrada na universidade, sendo a primeira causa apontada o seu próprio desempenho, e a segunda, a atuação dos professores. Resultados semelhantes quanto a não saber estudar antes da entrada na universidade, também foram observados no estudo de Mercuri (1992). 
Tabela 4. Dificuldades na redação dos trabalhos solicitados pelo professor

\begin{tabular}{|c|c|c|c|c|c|c|c|c|c|c|c|c|c|c|c|c|}
\hline & \multicolumn{8}{|c|}{ DIURNO } & \multicolumn{8}{|c|}{ NOTURNO } \\
\hline & \multicolumn{2}{|c|}{ Psicologia } & \multicolumn{2}{|c|}{ Engenharia } & \multicolumn{2}{|c|}{ Farmácia } & \multicolumn{2}{|c|}{ Total } & \multicolumn{2}{|c|}{ Psicologia } & \multicolumn{2}{|c|}{ Engenharia } & \multicolumn{2}{|c|}{ Farmácia } & \multicolumn{2}{|c|}{ Total } \\
\hline & $\mathrm{F}$ & $\%$ & $\mathrm{~F}$ & $\%$ & $\mathrm{~F}$ & $\%$ & $\mathrm{~F}$ & $\%$ & $\mathrm{~F}$ & $\%$ & $\mathrm{~F}$ & $\%$ & $\mathrm{~F}$ & $\%$ & $\mathrm{~F}$ & $\%$ \\
\hline 1 & 7 & 77.78 & 22 & 78,57 & 16 & 61,54 & 45 & 72.63 & 9 & 26.47 & 25 & 69,45 & 30 & 73,17 & 64 & 56,36 \\
\hline 2 & 1 & 11,11 & 5 & 17,86 & 5 & 19,23 & 11 & 16,07 & 9 & 26,47 & 5 & 13,89 & 2 & 4,88 & 16 & 15,08 \\
\hline 3 & 1 & 11,11 & 0 & 0 & 2 & 7,69 & 3 & 6,27 & 14 & 41,18 & 3 & 8,33 & 4 & 9.76 & 21 & 19.76 \\
\hline 4 & 0 & 0 & 1 & 3,57 & 3 & 11,54 & 4 & 5,03 & 2 & 5,88 & 3 & 8,33 & 5 & 12,19 & 10 & 8,8 \\
\hline Total & 9 & 100 & 28 & 100 & 26 & 100 & 63 & 100 & 34 & 100 & 36 & 100 & 41 & 100 & 111 & 100 \\
\hline
\end{tabular}

1- Não tem dificuldades na redação dos trabalhos: 2- Sim. e decorrem principalmente de problemas pessoais: 3- Sim. e decorrem principalmente de aspectos inerentes ao trabalho: 4- Sim. e decorrem principalmente da falta de orientação do professor.

Confirmando estes resultados, Andrade e Sposito (1986) concluíram que as dificuldades de aprendizagem dos sujeitos analisados foram decorrentes da trajetória acadêmica, refletindo os graus escolares anteriores ao curso superior, sempre vinculados à necessidade de conciliar trabalho e estudo.

\section{Considerações Finais}

Frente aos resultados e dados apresentados, algumas finais podem ser realizadas:

A maioria dos alunos afirmou não dispor de tempo suficiente para seus estudos, havendo diferenças significativas entre os turnos nos cursos de Farmácia e Engenharia noturnos em relação a essa questão. A razão principal da insuficiência de tempo para os estudos, principalmente entre os alunos do noturno, é atribuída ao fato de terem que dedicar grande palie do seu tempo ao trabalho.

Quanto ao período de estudo disponível, os alunos dos três cursos do diurno indicaram ter espaços para tanto distribuídos durante a semana e nos finais de semana. Por outro lado, a disponibilidade dos alunos do noturno é restrita, quase que exclusivamente, aos finais de semana. Verificou-se diferenças importantes em relação a esse aspecto: os alunos de Psicologia noturno concentram suas atividades de estudo nos finais de semana, enquanto os alunos de Farmácia noturno distribuem suas atividades de estudo ao longo da semana, quando comparados a seus colegas do período diurno.

Confirmou-se também, a importância verificada por outros estudos em relação à condição temporal, principalmente entre os alunos do noturno, os quais mais freqüentemente declararam sentirem-se prejudicados pela falta de tempo para maior dedicação às atividades de estudo extraclasse.

Entre as condições pessoais analisadas, o sono e o cansaço foram os fatores apontados como os mais comprometedores do rendimento acadêmico pelos alunos do noturno. Diferenças estatisticamente significantes foram detectadas entre os alunos dos cursos de Psicologia e Engenharia noturnos em relação aos alunos do diurno dos mesmos cursos.

O atraso e a ausência às aulas não são sentidos pela maioria como prejudiciais ao rendimento acadêmico. Dos que declararam sentirem-se prejudicados por estes fatores, os principais motivos alegados foram as tarefas da universidade entre os alunos do diurno e as tarefas extra-universidade entre os alunos do noturno. 
Em relação à dificuldades de compreensão em textos e/ou redação, foram os alunos de Psicologia noturno, os que mais apontaram ter dificuldades em compreender e/ou redigir um texto, sendo que tais dificuldades estão relacionadas com fatores de ordem pessoal e aspectos ligados ao texto.

Considerando as limitações do presente estudo no que diz respeito ao próprio instrumento e ao pequeno número de sujeitos frente à amplitude do universo do alunado, é importante que alguns cuidados com generalizações indevidas sejam tomados.

Mesmo assim, é possível sugerir que o conjunto de informações aqui levantadas seja utilizado para algumas reflexões sobre as condições institucionais oferecidas e para eventuais decisões, tanto no que se refere à capacitação dos professores para a utilização de estratégias de ensino-aprendizagem mais adequadas ao perfil e condições dos alunos dos diferentes cursos e turnos, como também para o oferecimento de programas suplementares aos próprios alunos, de modo a favorecer a aquisição de hábitos de estudo mais adequados às exigências de preparação profissional do mundo atual.

\section{Referências}

Andrade, C. L. \& Sposito, M. P. (1986). o Aluno do Curso Superior Noturno: Um Estudo de Caso. Cadernos de Pesquisas. São Paulo, 57, 3-19.

Balzan, N. (1988). A Didática e a Questão da Qualidade do Ensino Superior, Caderno Cedes, Campinas, 22, 53-66.

Castanho, M. E. (1989). Universidade à Noite: Fim ou Começo de Jornada? Campinas: Papirus.

D'Ydewalle, G.; Swerts, A. \& Corte, E. (1983). Study Time and Test Performance as a Function of Test Expectations. Contemporary Educational Psychology. 8,55-67.

Dominguez, S. F. \& Morelli, L. H. (1985). Levantamento das Dificuldades por Alunos do Terceiro Grau. Ciência e Cultura, 37 (7),1076-1089.

Fernandez, S. A. F. (1993). Ensino Superior Privado no Brasil: A Ótica do Discente. Tese de Doutorado, Faculdade de Educação, USP.

Hoirisch, A.; Barros, D. I. M. \& Souza, I. S. (1993). Orientação psicopedagógica no ensino superior. São Paulo: Cortez.

Keith, T. Z. (1982). Time Spent on Homework and High School Grades: A Large Sample Path Analisys. Journal of Educational Psychology, 74,248-253.

Marshak, D. \& Burkle, C. R. (1981). Learning to Study: A Basic Skill. Principal, 38-40.

Mercuri, E. (1992). Condições Espaciais. Materiais, Temporais e Pessoais para o Estudo. Segundo Depoimentos de Alunos e Professores de Cursos de Graduação da Unicamp. Tese de Doutorado, Faculdade de Educação, UNICAMP.

Morgan, C. T. \& Deese, J. (1980). Como Estudar. R.l.; Livraria Freitas Bastos S.A. (Original em Inglês: How to Study, 1975).

Oliveira, M. H. M. A. (1993). A Leitura do Universitário: Estudo Comparativo entre os Cursos de 
Engenharia e Fonoaudiologia da PUCCampinas. Dissertação de Mestrado, Departamento de Pós-Graduação em Psicologia - PUCCampinas.

Paul, J. J. \& Ribeiro, Z. D. (1991). As Condições de Vida e de Trabalho dos Alunos do Ensino Superior Brasileiro - O Caso das Universidades de Fortaleza. Educação Brasileira. Brasília, 13 (26),71-127.

Pellegrini, M. C. K. (1996). Avaliação dos Níveis de Compreensão e Atitudes frente à Leitura em Universitários. Dissertação de Mestrado, Faculdade de Filosofia Ciências e Letras, USF.

Santos, A. A. A. (1990a). Compreensão em leitura na universidade: um estudo comparativo entre dois procedimentos de treino. Estudos de Psicologia, Campinas, 7 (2), 39-53.

Santos, A. A. A. (1990b). Leitura e Universidade: uma análise de algumas questões críticas. Trans-in-formação, Campinas, 2 (2/3), 91-104.

Santos, A. A. A. (1996). Psicopedagogia no $3^{\circ}$ Grau: avaliação de um programa de remediação em leitura e estudo. Pro-posições. Campinas, 8, I (22),27-37.

Serpa, M. N. F. (1998). Serviço de Atendimento ao Universitário: Inserção e Atuação do Psicólogo Escolar. Disseliação de Mestrado, Faculdade de Filosofia Ciências e Letras - USF.

Sonneville, 1. J. (1992). O Tempo de Estudo e de Trabalho do Aluno Universitário - Um Estudo de Caso da F AEEBA. Revista F AEEBA. Bahia, 1(1), 63-78.

Souza, l. T. P. (1993). Estudo do Aluno Universitário para a Construção de um Projeto Pedagógico. Série Documental: Instituto Nacional de Estudos e Pesquisas Educacionais. (INEP): Relatos de Pesquisas, Brasília.

Recebido em fevereiro 1999. Encaminhado para revisores em fevereiro 1999.

Aprovado em maio 1999. 